\title{
Co-culturing experiments reveal the uptake of myo-inositol phosphate synthase (EC 5.5.1.4) in an inositol auxotroph of Saccharomyces cerevisiae
}

\author{
Erika Steele ${ }^{1}$, Hana D. Alebous ${ }^{2}$, Macy Vickers ${ }^{3}$, Mary E. Harris ${ }^{3}$ and Margaret D. Johnson ${ }^{3 *}$ (1)
}

\begin{abstract}
Background: Myo-Inositol Phosphate Synthase (MIP) catalyzes the conversion of glucose 6- phosphate into inositol phosphate, an essential nutrient and cell signaling molecule. Data obtained, first in bovine brain and later in plants, established MIP expression in organelles and in extracellular environments. A physiological role for secreted MIP has remained elusive since its first detection in intercellular space. To provide further insight into the role of MIP in intercellular milieus, we tested the hypothesis that MIP may function as a growth factor, synthesizing inositol phosphate in intercellular locations requiring, but lacking ability to produce or transport adequate quantities of the cell-cell communicator. This idea was experimentally challenged, utilizing a Saccharomyces cerevisiae inositol auxotroph with no MIP enzyme, permeable membranes with a $0.4 \mu \mathrm{m}$ pore size, and cellular supernatants as external sources of inositol isolated from S. cerevisiae cells containing either wild-type enzyme (Wt-MIP), no MIP enzyme, auxotroph (Aux), or a green fluorescent protein (GFP) tagged reporter enzyme (MIP- GFP) in co- culturing experiments.

Results: Resulting cell densities and microscopic studies with corroborating biochemical and molecular analyses, documented sustained growth of Aux cells in cellular supernatant, concomitant with the uptakeof MIP, detected as MIP-GFP reporter enzyme. These findings revealed previously unknown functions, suggesting that the enzyme can: (1) move into and out of intercellular space, (2) traverse cell walls, and (3) act as a growth factor to promote cellular proliferation of an inositol requiring cell.

Conclusions: Co-culturing experiments, designed to test a probable function for MIP secreted in extracellular vesicles, uncovered previously unknown functions for the enzyme and advanced current knowledge concerning spatial control of inositol phosphate biosynthesis. Most importantly, resulting data identified an extracellular vesicle (a nonviral vector) that is capable of synthesizing and transporting inositol phosphate, a biological activity that can be used to enhance specificity of current inositol phosphate therapeutics.
\end{abstract}

Keywords: Inositol auxotroph, Saccharomyces cerevisiae, Myo-inositol Phosphate Synthase (MIP), Protein secretion, Cellular supernatant, Extracellular vesicle, Co-culturing

*Correspondence: majohnso@ua.edu

${ }^{3}$ Department of Biological Sciences, The University of Alabama, PO Box 870344, Tuscaloosa, AL 35487, USA

Full list of author information is available at the end of the article

\section{Background}

Inositol phosphate, the product of MIP catalysis, and its phosphorylated derivatives are ubiquitous in all kingdoms of life and play vital roles in the spatial organization of central signaling pathways, including membrane trafficking, stress response, autophagy, neurodegenerative original author(s) and the source, provide a link to the Creative Commons licence, and indicate if changes were made. The images or other third party material in this article are included in the article's Creative Commons licence, unless indicated otherwise in a credit line to the material. If material is not included in the article's Creative Commons licence and your intended use is not permitted by statutory regulation or exceeds the permitted use, you will need to obtain permission directly from the copyright holder. To view a copy of this licence, visit http://creativecommons.org/licenses/by/4.0/. The Creative Commons Public Domain Dedication waiver (http://creativeco mmons.org/publicdomain/zero/1.0/) applies to the data made available in this article, unless otherwise stated in a credit line to the data. 
disorders, and polycystic ovary syndrome [1-9]. Inositol phosphate, the immediate precursor of free inositol, is generated from a tightly coupled oxidation and reduction reaction that requires $\mathrm{NAD}^{+}$to proceed [6]. Proposed intermediates of this reaction, 5- ketoglucose 6-phosphate and inose, 2,1-phosphate, have not been isolated; it is believed that they remain tightly bound to the enzyme [6]. Due to the presence of MIP in a diverse array of prokaryotic and eukaryotic organisms, it is speculated that inositol phosphate biosynthesis arose early during evolution $[10,11]$. MIP is the only enzyme known to catalyze the conversion of glucose- 6 phosphate into inositol phosphate $[6,12]$.

Early experiments, utilizing bovine brain and plants (Arabidopsis thaliana, Phaseolus vulgaris), and model eukaryote, S. cerevisiae, indicated that MIP associates with membranes and is secreted [13-17]. The discovery of MIP in yeast extracellular vesicles supports present and past research results concerning MIP location in intercellular space and organelles [15-22].

Importantly, the detection of MIP in extracellular vesicles established a basis for questioning the function of MIP in vesicles and for testing the hypothesis that MIP may function as a growth factor.

Extracellular vesicles have emerged as important mediators of intra- and intercellular communication [23-29]. They have been found to regulate a varied range of biological processes, and their pathophysiological roles are recognized in diseases such as neurodegenerative disorders, diabetes, and cancer [30-32]. Furthermore, extracellular vesicles have been detected in cerebrospinal fluid, an intermediary between blood and brain, in addition to other fluids, including saliva and seminal fluids [31]. Numerous investigations have shown that extracellular vesicles can be taken up and their internal contents act as signals [33-37].

Moreover, it has been shown that fungal cells produce extracellular vesicles, which share morphological and biochemical similarities with mammalian exosomes $[17,33]$, including an ability to modulate the function of immune cells [33]. Plant cells also produce exosome-like vesicles [38], supporting the notion that vesicular release is a mechanism of trans-cell wall passage shared by cellwall containing eukaryotes [38]. Thus, defining a function for MIP in extracellular vesicles broadens knowledge of the spatial control of inositol phosphate biosynthesis and enhances possibilities for controlling inositol phosphate metabolism in health and in disease.

Co-culturing experiments have been widely used to study cellular functions, such as transport, absorption, secretion, and cell-cell communication, since the pioneering, transfilter, metanephric induction studies of Grobstein [39]. Therefore, we employed an updated version of this technique to assess the ability of MIP to function as a growth factor [40, 41].

Supernatant from yeast cells containing either Wt-MIP enzyme (positive control), no MIP enzyme, Aux, (negative control), or MIP-GFP (enzyme tagged with GFP for detection) was employed to assess growth of an inositol auxotroph, Aux, in a cellular environment, which required external inositol. Results of transwell co- culturing experiments, designed to test these three different cellular supernatants for their ability to provide a source of inositol and sustain growth of an inositol requiring cell, are reported here.

\section{Results}

\section{Validating the use of a GFP tagged MIP enzyme} in co-culturing experiments

To certify the use of a tagged enzyme in co-culturing experiments, microscopic, biochemical, and protein structural studies were employed to compare functional and conformational integrity of a GFP tagged MIP enzyme, MIP-GFP, (Table 1) with that of an untagged, wild-type MIP enzyme (Wt-MIP), (Table 1). Digital images obtained with a confocal microscope, equipped with DIC imaging capacity, showed that MIP-GFP fluorescence is associated with internal membranes, the cell wall, and the extracellular vesicles (Fig. 1). Likewise, detailed transmission electron microscopic (TEM) micrographs of Wt-MIP expression reflected confocal data, detecting Wt-MIP enzyme expression in equivalent cellular structures, including cell walls and extracellular vesicles (Fig. 2). Moreover, subsequent biochemical analyses, including protein purification, enzyme assays, and protein modeling, established functional and conformational integrity of MIP-GFP. Crystal structures and active site maps of a highly conserved enzyme allowed the creation of 3-dimensional (3-D) models of Wt-MIP and MIP-GFP, demonstrating conformational change with functional conservation (Fig. 3A-C). In addition, the local RMSD (root mean square deviation) for the two models, $1.61 \AA$ A.is less than $2.0 \AA$, indicating that the active site of the enzyme is not affected by the presence of GFP in MIP structure. In contrast,, a global RMSD of $3.65 \AA$ is greater than $2.0 \AA$, reflecting structural differences between the models. This result is not surprising,

Table 1 S. cerevisiae strains utilized in co-culturing experiments

\begin{tabular}{ll}
\hline Yeast strain & Genotype \\
\hline SH 477 (Wild-Type) (Wt-MIP)* & (MATa, URA3) \\
INO1 $\triangle$ (Deleted INO1 Gene)* & (MATa, URA3, INO1) \\
MIP:GFP(INO1:GFP fusion gene) & (MATa, URA3, INO1:GFP) \\
\hline
\end{tabular}

*Yeast strains were gifts from Dr. Susan Henry (Culbertson and Henry, 1975) 

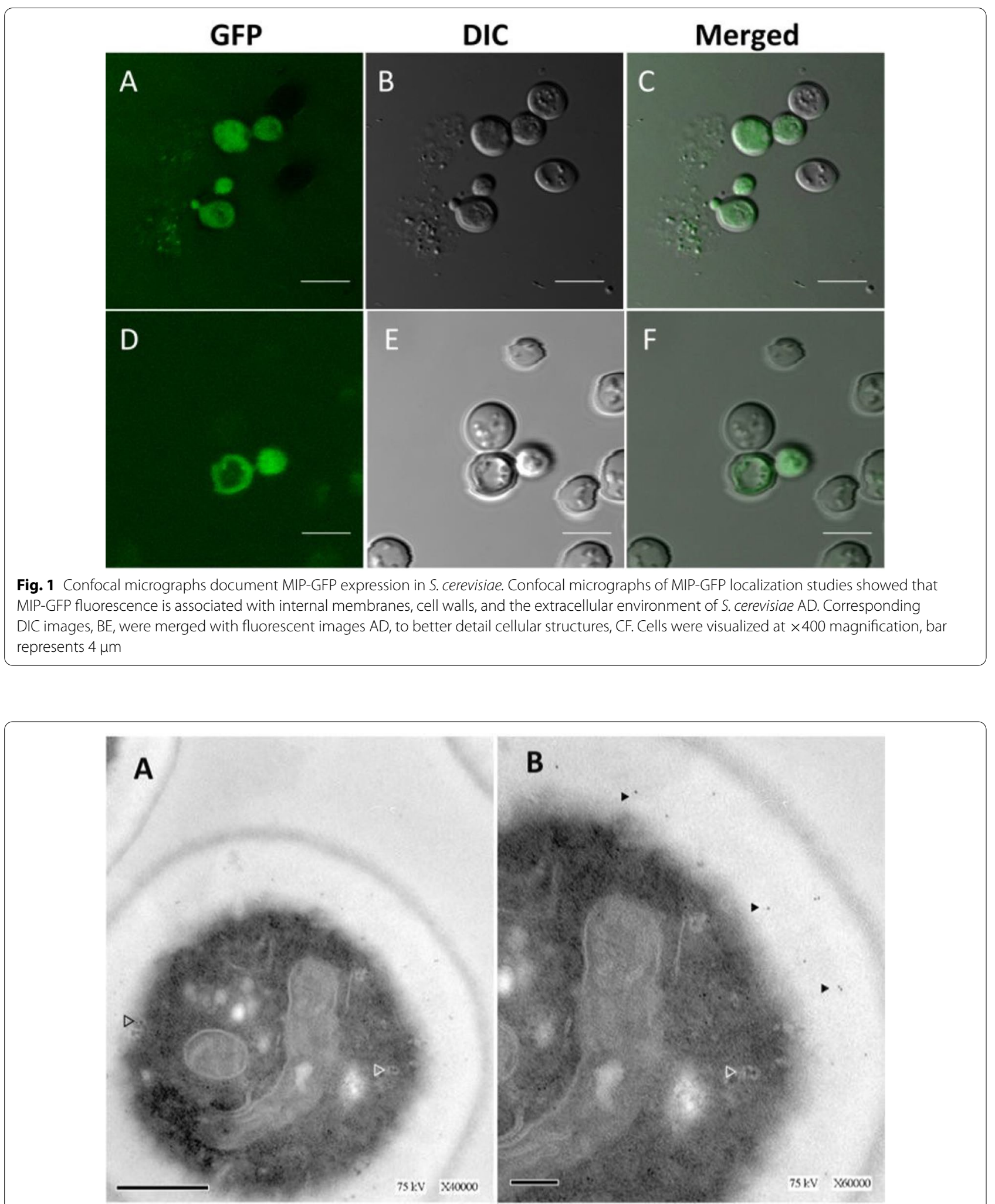

Fig. 2 TEM studies detect Wt-MIP expression in extracellular vesicles of S. cerevisiae. TEM photomicrographs of MIP expression in Wt-MIP identified internal membranes, cell walls, and vesicles as sites of MIP expression A, B. Vesicles transporting MIP are associated with internal membranes (open arrows) and with the cell wall (closed arrows). Bar denotes $5 \mu \mathrm{m}, \mathbf{A}$, and a magnification of $\times 40,000$. In $\mathbf{B}$, the bar represents $2 \mu \mathrm{m}$ and a magnification of $\times 60,000$. Cells were viewed at two different magnifications to better capture MIP localization and transport in vesicles 
A

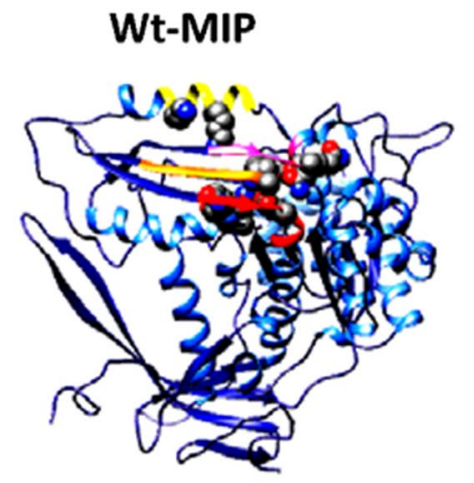

C
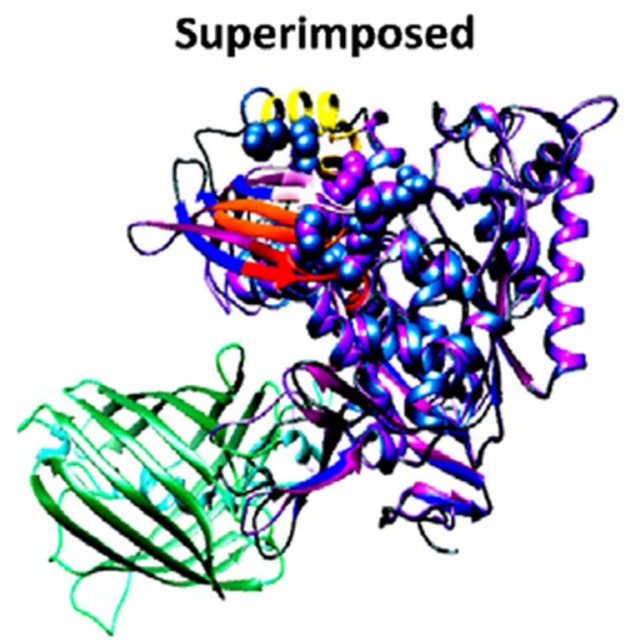

B

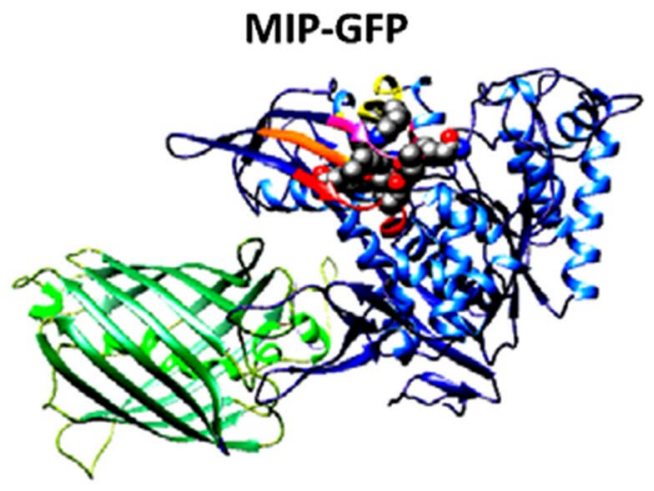

D

\begin{tabular}{|c|c|c|}
\hline Strain & $\begin{array}{c}\text { Average Total Activity } \\
\text { Units ( } \pm \text { SD) }\end{array}$ & $\begin{array}{l}\text { Specific Activity } \\
\text { Units/mg } 10^{-3 *} \\
\end{array}$ \\
\hline \multicolumn{3}{|c|}{ Microsomes } \\
\hline Wt-MIP & $66.1 \pm 33.7$ & 33.1 \\
\hline MIP-GFP & $59.8 \pm 31.1$ & 29.9 \\
\hline \multicolumn{3}{|c|}{ Soluble Protein } \\
\hline Wt-MIP & $49.07 \pm 7.7$ & 4.9 \\
\hline MIP-GFP & $52.55 \pm 14.1$ & 5.2 \\
\hline \multicolumn{3}{|c|}{ Mitochondria } \\
\hline Wt-MIP & $9.8 \pm 7.0$ & 4.9 \\
\hline MIP-GFP & $16.9 \pm 3.7$ & 8.5 \\
\hline
\end{tabular}

Fig. 3 Comparative 3-D modeling of MIP-GFP and Wt-MIP proteins. 3-D protein models of Wt-MIP and MIP-GFP were created in PHYRE-2 [62]. Proteins are colored coded with Wt-MIP shown in (Blue) A MIP-GFP (Blue/Green) B Superimposed images [66] display Wt-MIP in (Blue) and MIP-GFP (Purple/Green), C MIP-GFP catalytic activity was compared to that of Wt-GFP, D Basak et al. [65] described six highly conserved amino acid patterns found in active sites of crystal structures from eukaryotes and prokaryotes. Four of the most highly conserved motifs are colored: HNVCEDSLL (Red), DSKVAMDEY (Orange), FRSKEISKS (Yellow), and YNHLGNNDG (Pink). Highly conserved amino acids, Ser323, Gly324, Gln325, Thr326, Lys369, Lys373, Lys412 and Lys489, are thought to be important for catalytic activity [65]. The local RMSD (root mean square deviation) for the two models, $1.61 \AA$, is $<2.0 \AA$, whereas the global RMSD, $3.65 \AA$, is $>2.0 \AA$. These RMSD values specify a conformational change with functional conservation [66]

given that Wt-MIP and MIP-GFP are expected to be dissimilar in the region where GFP sequence has been inserted into MIP sequence (Fig. 3A-3C). Enzyme activity assays and microscopic examinations showed that both MIP and GFP are functional in the fusion protein. Also, enzymatic activity detected in soluble and organelle proteins, supported equivalent subcellular locations identified in microscopic images (Fig. 3D).

Also, enzymatic activity detected in soluble and organelle proteins, supported equivalent subcellular locations identified in microscopic images (Fig. 3D). However, further characterization of organelles, employing western blotting, showed that MIP-GFP in the plasma membrane had a reduced response to regulation by exogenous inositol (Fig. 4D). Unlike Wt-MIP, MIP-GFP plasma membrane protein is not completely repressed when grown in the presence of exogenous inositol (Fig. 4D). It is known that cytoplasmic MIP is highly regulated by feedback inhibition of its end product, inositol, in S. cerevisiae (Fig. 4D). It appears that GFP inserted into the carboxyl, C-terminus, of MIP diminishes its robust response to exogenous inositol (Fig. 4D). This change may affect its movement into and out of plasma membranes without disturbing its 


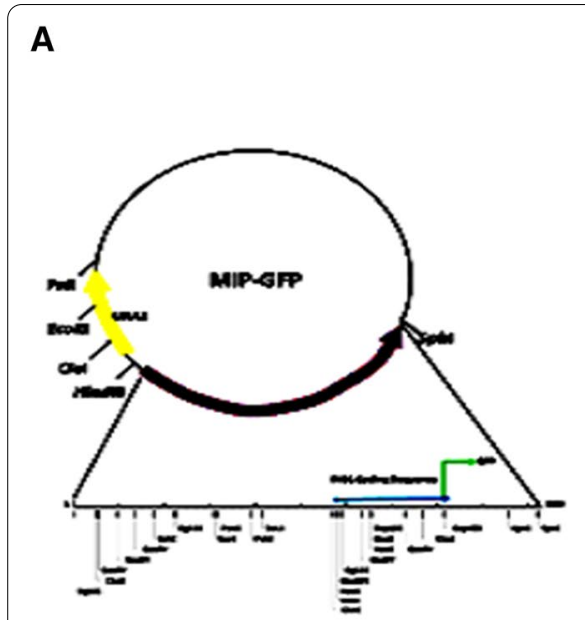

B

MAP-GFP

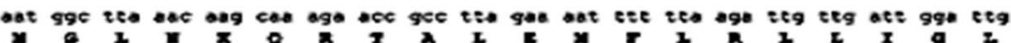

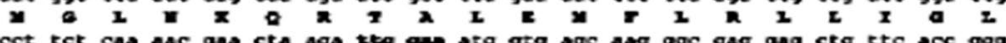

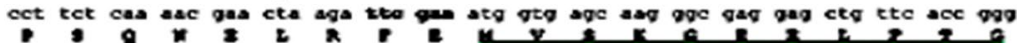

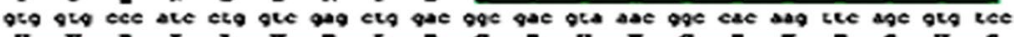

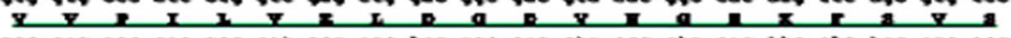

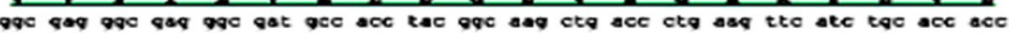

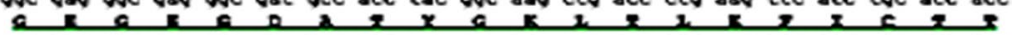

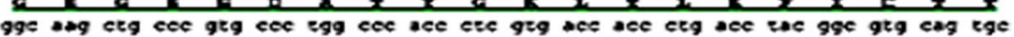

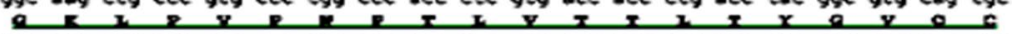

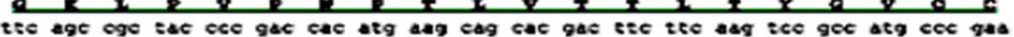

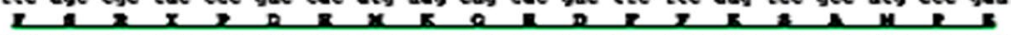

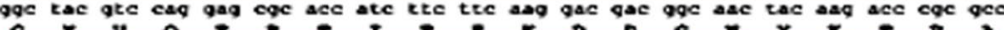

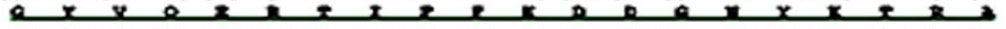

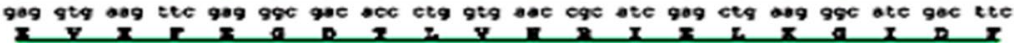

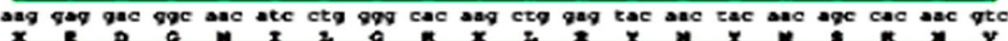
$x<x<x$

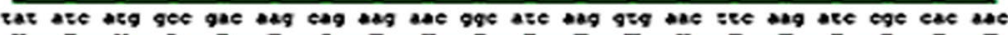

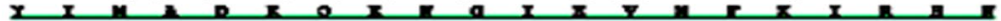

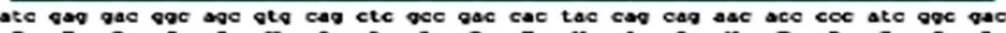

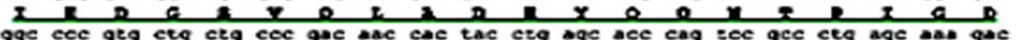

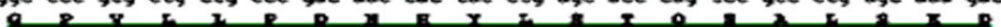
ece aac gag asg oge gat cac atg gte etg etg gag tec gtg ace ges gec ggg ate act

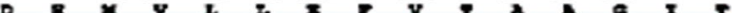

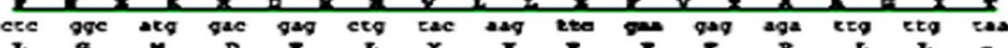

C

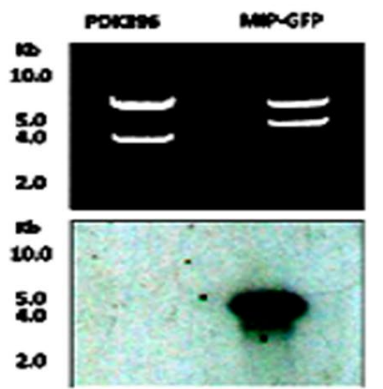

D

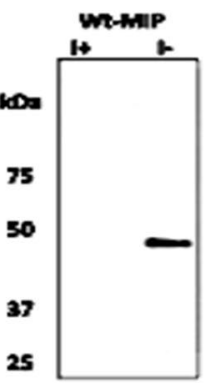

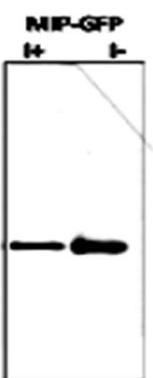

Fig. 4 Construction of a MIP-GFP reporter enzyme. The complete INO1 gene, located on a 4.2 kb Hind III- Kpn I restriction enzyme fragment, was cloned into a high copy number plasmid vector, pDK 396. A [51,52], The plasmid was used to construct an INO1: GFP fusion gene, encoding a fluorescent MIP-GFP reporter enzyme. The INO1 gene encodes MIP in S. cerevisiae [51, 52]. A GFP gene [53], with Csp45I restriction site adapters, was inserted into a Csp45I restriction enzyme site (shown in bold type) located at the 3 prime end of INO1. DNA sequencing and bioinformatics analyses confirmed the correct reading frame, GFP is underlined. B while polymerase chain reaction cloning, using gene specific primers [54] and Southern blotting [55] confirmed the correct genomic location of the fusion gene after its integration into the yeast genome, using homologous recombination as described by Huh et al.[56], replacing resident genomic copy of the INO1 gene, (C). Western blotting studies of MIP-GFP and WT-MIP organelles, found that MIP-GFP in the plasma membrane is less sensitive to inositol feedback inhibition than Wt-MIP (D)

catalytic activity, since all known active sires are preserved in the conformational change of MIP-GFP (Fig. 3A-C).

\section{Supernatant sources of inositol can sustain growth}

The idea that secreted MIP enzyme in the extracellular environment may function as a growth factor was challenged using a transwell co- culturing experimental approach [39-41]. A critical component of this method involved utilizing permeable membranes with extremely small pore sizes, $0.4 \mu \mathrm{m}$, in the upper chamber of the culture dish to prevent contamination or mixing of other cells with Aux cells. Since S. cerevisiae cells can vary greatly in size, anywhere from $4-10 \mu \mathrm{m}$, it was necessary to utilize $0.4 \mu \mathrm{m}$, the smallest pore size available.
Densities of Aux cells, grown in the presence of supernatant from Wt-MIP, Aux, or MIP-GFP cells, were calculated after measuring the OD660 with a Genesys 2 spectrophotometer [42]. Cell densities for three different transwell co- culturing experiments are reported (Fig. 5). Statistical analyses and a plot of mean values show that there are significant differences in growth between the study samples $(\mathrm{p}<0.05)$. A bar graph compares and illustrates these differences in cell densities (Fig. 5A). Blue bars denote sustained growth and efficient utilization of Wt-MIP supernatant as a source of inositol for Aux cells, while green bars indicate that supernatant from Aux cells cannot serve as an external source of inositol. Aux cells utilizing Aux cellular supernatant as a source of external inositol, failed to proliferate. Yellow bars illustrate limited 


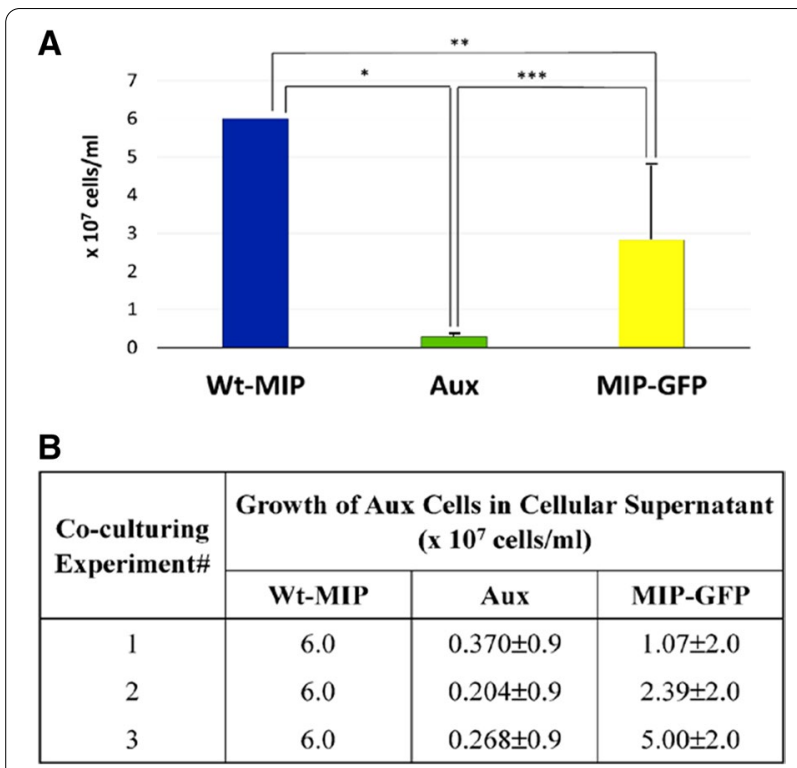

Fig. 5 Growth of Aux cells in cellular supernatant. A bar graph, A, created from cell densities, $\mathbf{B}$, illustrates and compares growth of Aux cells in three different transwell co-culturing experiments. Data documented sustained growth of Aux cells in Wt- MIP supernatant (positive control) (blue bar), no growth in Aux supernatant (negative control) (green bar), and mixed growth in supernatant from cells containing MIP-GFP reporter enzyme (yellow bar). ANOVA analyses and a plot of mean values show that there are significant differences in growth between the study samples $(p<0.05)$

growth of Aux cells consuming MIP-GFP supernatant as a source of inositol (Fig. 5). One plausible explanation for this occurrence is the finding that MIP-GFP has a reduced response to feedback inhibition by exogenous inositol in the plasma membrane, which may alter its ability to move efficiently into and out of plasma membranes, decreasing the amount of MIP-GFP protein present in the supernatant. Good growth in MIP-GFP supernatant requires efficient movement and concentration of extracellular vesicles in the intercellular environment, as with Wt-MIP. Given that mechanisms of transport and uptake are unknown and that all physical parameters are constant, the number of cells in each MIP-GFP growth experiment would depend on the number of vesicles free to move into and out of the supernatant. This number appears to slowly increase in MIP-GFP supernatant (Fig. 5).

\section{Microscopic examination of Aux cells grown in supernatant sources of inositol}

Given the results of transwell co-culturing experiments, utilizing cellular supernatants as external sources of inositol, and the fact that MIP has been detected in extracellular vesicles [15-17], it was imperative that we assess the fate of MIP-GFP secreted into the extracellular milieu of Aux cells. Toward this end, Aux cells were subjected to confocal studies, utilizing a confocal microscope with DIC imaging capacity, to visualize cells with both visible and fluorescent wavelengths (Figs. 6, 7, and 8).

Aux cells, located in the lower chamber of the culture dish, were removed and prepared as described then examined for MIP-GFP expression. Since GFP tagged molecules should only glow under FITC wavelengths, all cells were examined for contamination by switching wavelengths and evaluating cells for continued glow under YFD, Cherry, and TRIC settings as well. Common

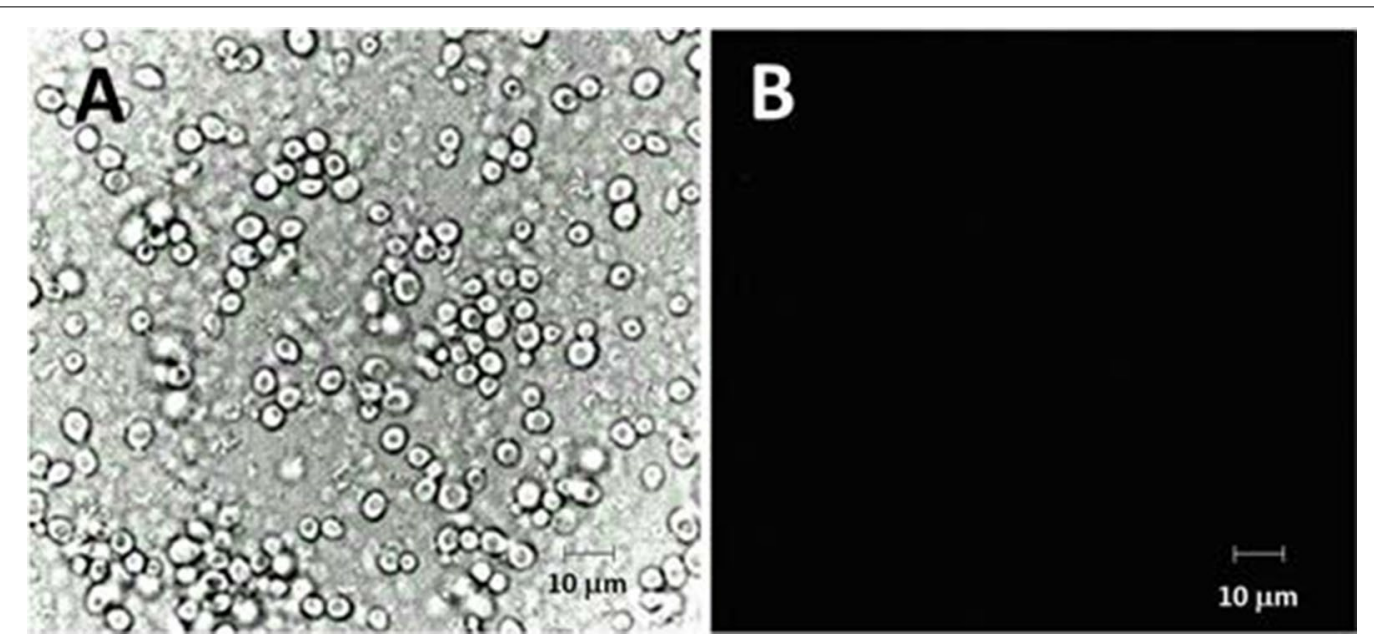

Fig. 6 Growth of Aux cells utilizing Wt-MIP cellular supernatant as a [43] source of exogenous inositol. Micrographs, captured with visible light, show excellent growth of auxotrophic cells utilizing Wt-MIP cellular supernatant as an exogenous source of inositol 4A. Images taken with FITC wavelengths indicated that these cells contained no GFP or other contaminating fluorescent molecules 4B. Cells were examined for contamination by switching wavelengths and evaluating cells for continued glow under FITC, YFP, Cherry, and TRIC settings 


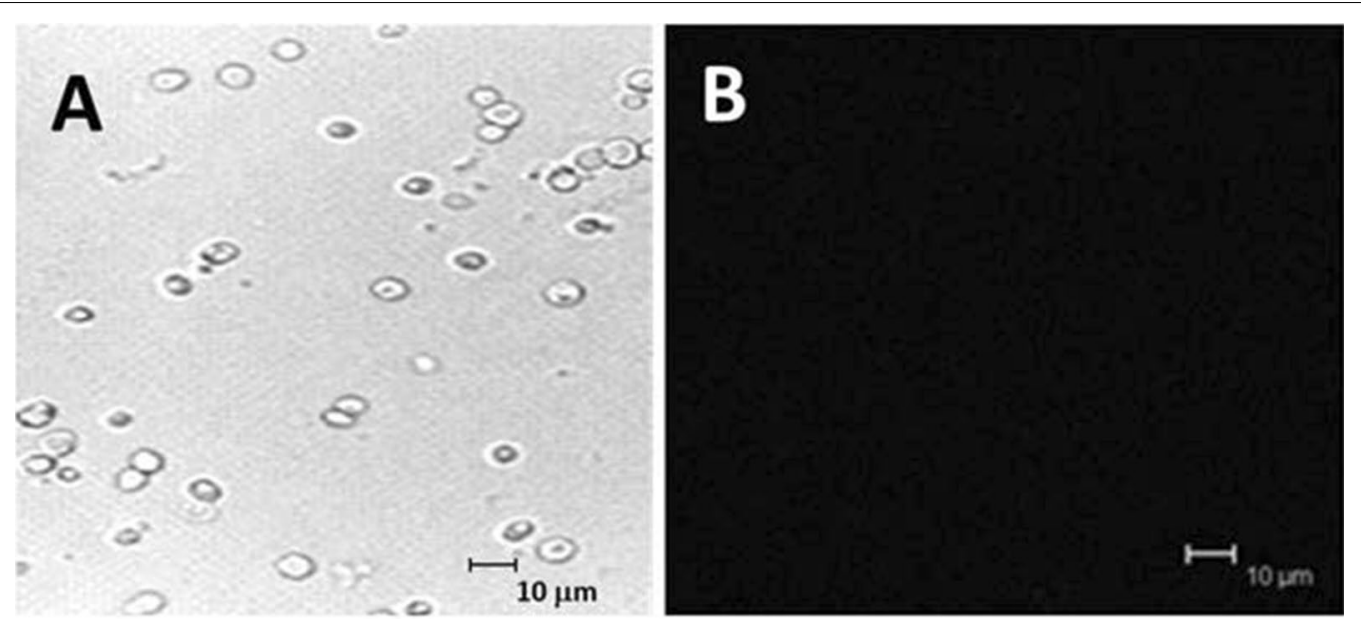

Fig. 7 Growth of Aux cells in Aux cellular supernatant as a [43] source of inositol. Confocal images, taken with visible light, showed that inositol requiring Aux cells cannot utilize auxotrophic cellular supernatant as a source of external inositol A. Low cell densities support this microscopic finding. Evaluating cells for continued glow under FITC, YFP, Cherry, and TRIC settings demonstrated a lack of contaminating fluorescent molecules B
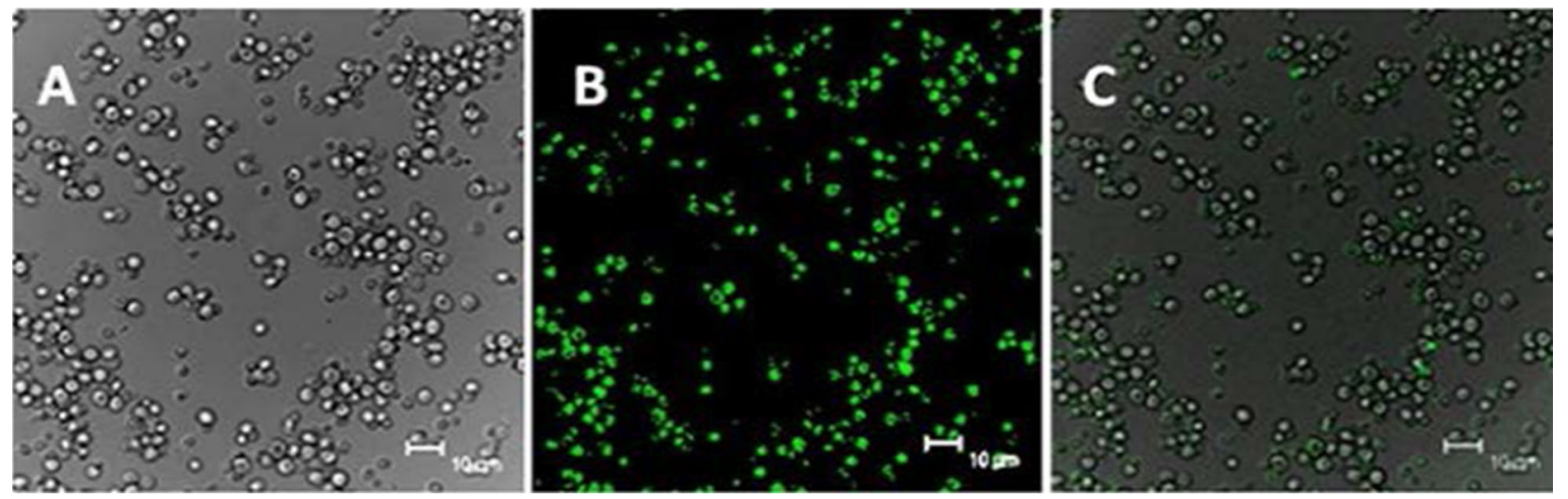

Fig. 8 Growth of Aux cells in MIP-GFP cellular supernatant. Light micrographs show sustained growth of Aux cells cultured in MIP-GFP supernatant as a source of inositol A. Moreover, Aux cells identified in FITC mode revealed the uptake of fluorescent MIP-GFP molecules B. Visible and fluorescent images, $\mathbf{A}$ and $\mathbf{B}$, respectively, were merged to show that MIP-GFP fluorescence aligns with cells $\mathbf{C}$

bacteria tend to give off fluorescence in a full spectrum of colors and are identified by this technique [43]. As shown in (Fig. 6), Aux cells grown in Wt-MIP supernatant were only visible with light (Fig. 6A), not fluorescent wavelengths (Fig. 6B), demonstrating that these cells did not contain MIP-GFP or any other contaminating fluorescent molecules. Moreover, cell densities indicated that Wt-MIP cellular supernatant provided an excellent, sustainable source of inositol for vigorous growth of Aux cells (5A). In contrast, supernatant from Aux cells could not sustain growth or function as a source of inositol (Fig. 7A). There was no proliferation of Aux cells, utilizing Aux supernatant. Additionally, cells weren't visible with fluorescent wavelengths, confirming the absence of contaminating fluorescent molecules (Fig. 7B). Fluorescence was only detected in Aux cells grown in supernatant from cells containing MIP tagged with GFP, revealing the uptake of MIP-GFP (Fig. 8B). Corresponding light microscopic analyses confirmed that MIP-GFP supernatant provided a good source of inositol for sustained growth of S. cerevisiae inositol requiring Aux cells (Fig. 8A).

\section{Discussion}

Movement of vesicles into and out of intercellular spaces is an evolutionarily conserved mode of cell-cell communication for diverse organisms, including prokaryotes and eukaryotes [26-28,44]. Current studies made use of 
a well-studied model eukaryote, $S$. cerevisiae, to examine the fate of MIP secreted in extracellular vesicles. Consequently, transwell co-culturing experiments uncovered previously unknown functions for the enzyme. Data show that: (1) a S. cerevisiae inositol Aux cells can sustain growth in the presence of cellular supernatant sources of inositol, (2) this growth depends on the uptake of MIP, and (3) MIP can traverse cell walls. A schematic of these findings is detailed in (Fig. 9). In nature, some cells, such as Schizosaccharomyces pombe, are natural auxotrophs of

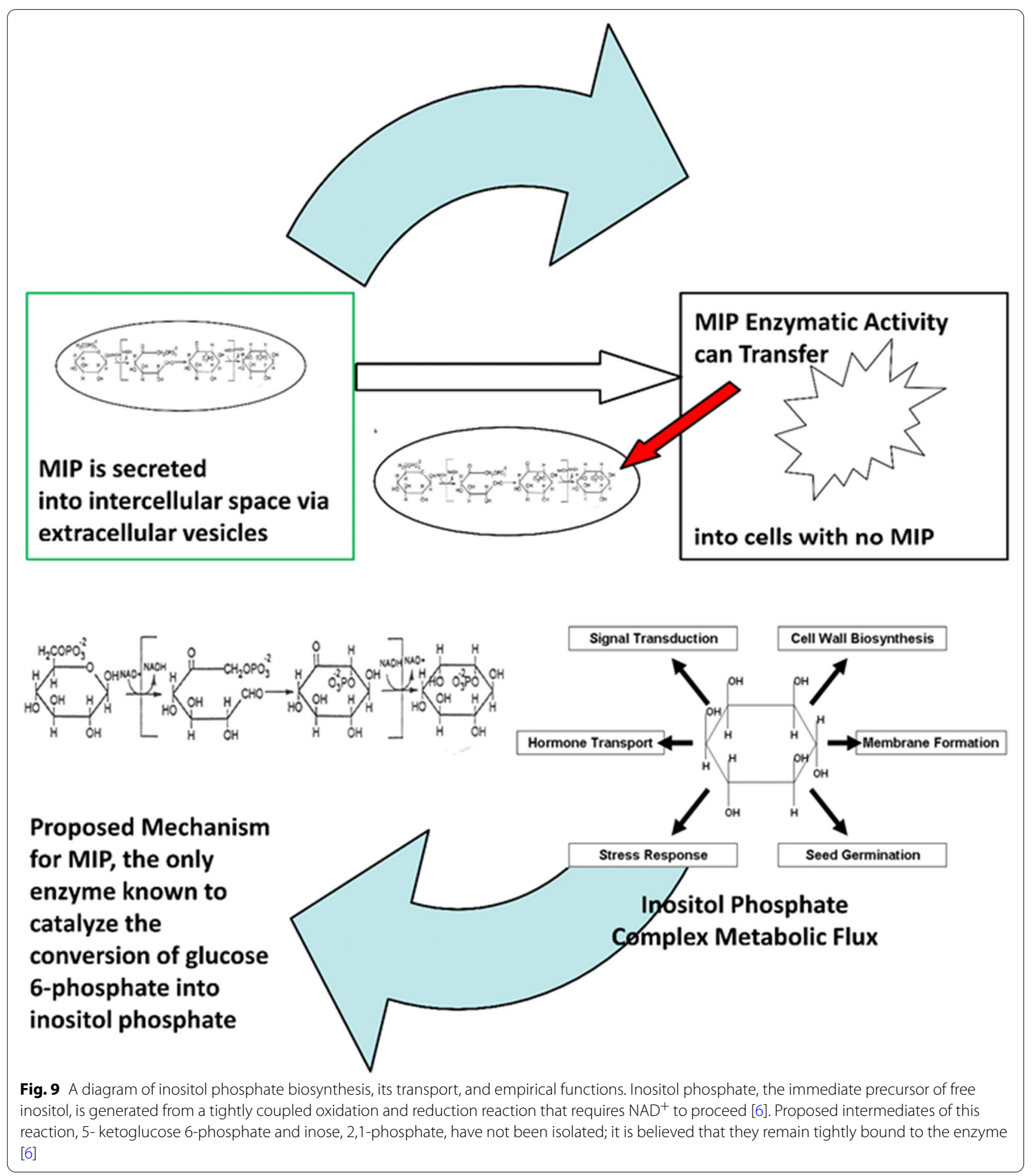


inositol, yet depend on the nutrient for cell viability [45, 46]. Still other cells, with biosynthetic capacity to convert glucose 6-phosphate into inositol phosphate, may experience cellular events, which mutate or inactivate the catalytic activity of MIP. All things considered, the presence of inositol phosphate biosynthetic competency in the intra and intercellular milieu confers a selective advantage to all cells requiring inositol for growth and communication with other cells, especially those in multicellular organisms. Present research data suggest that MIP plays a vital role in regulating the complex metabolic flux of inositol phosphate. Moreover, cycling inositol phosphate biosynthesis from intracellular to extracellular environments ensures that an essential nutrient and cellcell communicator is always available for its currently defined functions in all kingdoms of life, including central cell signaling pathways, membrane trafficking, stress response, autophagy, lipid metabolism, hormone transport, and neurodegenerative disorders [47, 48].Findings presented in this report have been demonstrated by others [49]. Published data show that fungal cells can bind and internalize extracellular vesicles [49]. This knowledge enhances their commercial potential, especially as it pertains to inositol production. A recent research article has demonstrated the complexity involved in engineering inositol production in bacterial cells [50]. Given the importance of inositol in many industries, including those related to health, pharmaceuticals, and agriculture, information presented here will allow a more efficient production of inositol and an extracellular vesicle in which to transport it.

\section{Conclusions}

In summary, co-culturing experiments, designed to test a probable function for MIP secreted in extracellular vesicles, uncovered previously unknown functions for the enzyme. Present data suggest that MIP can: (1) move into and out of intercellular space, (2) traverse cell walls, and (3) act as a growth factor to promote cellular proliferation in an inositol requiring cell. These findings advance current knowledge concerning spatial control of inositol phosphate biosynthesis. Consequently, we can now employ new experimental approaches to define mechanisms that regulate the complex metabolic flux of inositol phosphate biosynthesis and delineate the role of an essential enzyme, capable of synthesizing an indispensable cell-cell communicator, in the process. Most importantly, resulting data identified a non-viral vector, i.e. an extracellular vesicle, capable of synthesizing and transporting inositol phosphate, a biological activity that can be harnessed to enhance and advance specificity of current inositol phosphate therapeutics.

\section{Methods}

\section{S cerevisiae growth conditions}

Yeast strains utilized in all experiments are listed in Table 1. Cells were grown at $30^{\circ} \mathrm{C}$ in minimal medium (20 g glucose, $5.0 \mathrm{~g}$ ammonia acetate, $1.7 \mathrm{~g}$ yeast nitrogen base, $10 \mathrm{ml}$ complete amino acid solution, $20 \mathrm{ml}$ yeast vitamin solution per liter) with or without inositol or complete medium (20 g glucose, $20 \mathrm{~g}$ bactopeptone, $10 \mathrm{~g}$ yeast extract per liter).

\section{Construction and evaluation of a MIP-GFP reporter enzyme} The INO1 gene encodes the MIP enzyme in S. cerevisiae [51, 52]. Plasmid pDK396 [52], containing the complete INO1 gene located on a Hind lll- Kpn 1 restriction enzyme fragment, was used to construct an INO1: GFP fusion gene, encoding a fluorescent MIP-GFP reporter enzyme in S. cerevisiae cells. Specifically, a GFP gene [53], with Csp45I restriction site adapters, was inserted into a Csp45I restriction enzyme site located at the 3 prime end of INO1 (Fig. 4A). GFP is a 238 amino acid residue protein, which exhibits bright green fluorescence when exposed to light in the blue to ultraviolet range [53]. DNA sequencing and bioinformatics analyses confirmed the construct's correct reading frame, while polymerase chain reaction cloning [54] and Southern blotting [55]confirmed the correct genomic location of the fusion gene after its integration into the yeast genome, using homologous recombination as described by Huh et al.[56], replacing the resident genomic copy of the INO1 gene (Fig. 4C). Western blotting of organelle proteins [15] further confirmed the insertion of GFP into the genomic copy of INO1 (Fig. 4D).

\section{MIP-GFP activity was assessed in soluble and membrane fractions of $S$. cerevisiae Isolation of S. cerevisiae microsomes and mitochondria} Microsomes were isolated as described by Carmen and Fischl [58]. Yeast cells were grown overnight in yeast broth without inoitol. Microsomal fractions were further purified using a percoll density gradient [15]. Yeast mitochondria were isolated using a MITOISO3 kit (Sigma). Cells were grown overnight to a density of 1.3 (OD600), centrifuged at 3,000 g for $5 \mathrm{~min}$, and washed with sterile water. We further purified the mitochondria using a percoll gradient. First $150 \mu \mathrm{l}$ of percoll was added to each sample. resulting in a concentration of $15 \%$ percoll. Next, the samples to a were added to density gradient consisting of $2 \mathrm{ml}$ of the following, $40 \%$ percoll and 23\% percoll. Finally, the samples were centrifuged at $31,000 \mathrm{~g}$ for $15 \mathrm{~min}$ at $4{ }^{\circ} \mathrm{C}$ in a fixed angle rotor. Mitochondria were collected, diluted with 4 volumes of $1 \mathrm{X}$ storage buffer (Sigma), pelleted at $17,000 \mathrm{~g}$ for $15 \mathrm{~min}$ at $4{ }^{\circ} \mathrm{C}$ in a fixed 
angle rotor, concentrated in a Slide-A-Lyzer Mini Dialysis Unit (Pierce) and stored at $-20^{\circ} \mathrm{C}$. Isolated microsomes and mitochondria were solubilized overnight for purity and marker assays [15].

\section{Isolation of soluble proteins from S. cerevisiae}

Soluble proteins were isolated as described by Lackey et al. [15] with modifications. Yeast cells were grown in $100 \mathrm{ml}$ of media without inositol at $30^{\circ} \mathrm{C}$ to an OD 600 of $1-1.5$. Isolated soluble proteins were suspended in buffer containing a protease inhibitor cocktail (Roche).

\section{Assay for MIP-GFP catalytic activity}

MIP-GFP catalytic activity was evaluated according to Barnett et al.[57]. Soluble proteins $(0.01 \mathrm{mg})$ and solubilized purified organelles $(0.002 \mathrm{mg})$ were incubated as described. Phosphate concentrations, an indirect quantification of inositol phosphate, were measured in a Genesys 2 spectrophotometer at $820 \mathrm{nM}$ and calculated using a standard phosphate curve (Fig. 3).

\section{Confocal microscopic examination of MIP-GFP reporter enzyme}

For confocal studies, S. cerevisiae cells, expressing MIPGFP reporter enzyme, were grown overnight at $30{ }^{\circ} \mathrm{C}$ in minimal media without inositol. Wet mounts of cells were observed at 400X using a Leica Microsystems Heidelberg $\mathrm{GmbH}$.

\section{Preparation of cells for TEM studies of Wt-MIP expression} Cells of Wt-MIP strain SH 477 (Table 1), were grown to an OD660 of 1.0 in minimal medium without inositol supplementation and fixed for electron microscopy as described by Wright [59] with the following modifications. A 1:1 solution of yeast cell culture and fixative (0.2 M PIPES [pH 6.8], $0.2 \mathrm{M}$ sorbitol, $2 \mathrm{mM} \mathrm{MgCl}$, $0.2 \mathrm{mM} \mathrm{CaCl} 2,0.5 \%$ glutaraldehyde, $4 \%$ formaldehyde) was incubated at room temperature for $5 \mathrm{~min}$, centrifuged, suspended in fixative,diluted 1:1 in sterile water. Cells were collected, suspended in $25 \mathrm{ml}$ of sterile water, incubated for $10 \mathrm{~min}$, and pelleted at 1,500 RPM. Finally, after $2 \mathrm{X}$ washes in $25 \mathrm{ml}$ of sterile water, cells were suspended in $5 \mathrm{ml}$ of $1 \%$ sodium metaperiodate at room temperature for $15 \mathrm{~min}$. Following incubation, cells were collected at $1500 \mathrm{RPM}$, washed with $5 \mathrm{ml}$ of sterile water, suspended in $5 \mathrm{ml}$ of $50 \mathrm{mM}$ ammonium chloride, and incubated $15 \mathrm{~min}$ at room temperature.

Afterwards, cells were collected, washed $2 \mathrm{X}$ in sterile water, and collected via centrifugation. Following collection, cells were dehydrated in a graded series of ethanol from 60 to $100 \%$ for $10 \mathrm{~min}$ each, followed by infiltration and embedding [59], using London Resin (LR) Gold instead of LR-White. Polymerization of the resin was carried out by exposure to UV light for $48 \mathrm{~h}$. Thin sections were prepared and stained with uranyl acetate and lead citrate as described b y W r i g h t [59]. Stained grids were submerged in $20 \mathrm{ml}$ of TBSTO $(140 \mathrm{mM} \mathrm{NaCl}$, $3 \mathrm{mM} \mathrm{KCl}, 8 \mathrm{mM}, \mathrm{Na} 2 \mathrm{HPO} 4,1.5 \mathrm{mM} \mathrm{KH} 2 \mathrm{PO} 4,0.05 \%$ Tween-20, and $2 \%$ ovalbumin), transferred to yeast MIP antibody, diluted 1:1000 in TBSTO, and incubated for $2 \mathrm{~h}$ at room temperature in a moist chamber. Afterwards, grids were washed $3 \mathrm{X}$ in TBST $(140 \mathrm{mM} \mathrm{NaCl}, 3 \mathrm{mM}$ $\mathrm{KCl}, 8 \mathrm{mM}$, Na2HPO4, $1.5 \mathrm{mM} \mathrm{KH2PO4,} \mathrm{0.05 \%} \mathrm{Tween-}$ 20), submerged in $20 \mathrm{ml}$ of TBSTO, incubated for $15 \mathrm{~min}$, transferred to gold-conjugated secondary antiserum, diluted 1:100 in TBSTO, washed 3X in TBST, fixed with $5 \%$ glutaraldehyde in TBS $(140 \mathrm{mM} \mathrm{NaCl}, 3 \mathrm{mM} \mathrm{KCl}$, $8 \mathrm{mM}$, Na2HPO4, $1.5 \mathrm{mM} \mathrm{KH} 2 \mathrm{PO} 4)$ for $1 \mathrm{~h}$, washed $3 \mathrm{X}$ in TBST, followed by $3 \mathrm{X}$ washes in TBS and water, air dried, stained with uranyl acetate and lead citrate for TEM analyses.

\section{Transwell co-culturing experiments}

Co-culturing experiments utilized Corning ${ }^{\mathrm{TM}}$ transwell cell culture plates with twelve wells, six wells in an upper chamber of the plate with six corresponding wells in a lower chamber. Wells in the upper chamber contained polyester permeable membranes, $24 \mathrm{~mm}$ in diameter, $10 \mu \mathrm{m}$ thick, with $0.4 \mu \mathrm{m}$ pore sizes. To prepare inositol auxotrophic, Aux, cells for the lower chamber, cells were grown overnight at $30{ }^{\circ} \mathrm{C}$ in minimal medium with inositol to prevent inositol-less death [60], centrifuged, washed $2 \mathrm{X}$ in minimal medium without inositol, and diluted in minimal medium without inositol to a final concentration of $0.128 \times 10^{7}$ cells $/ \mathrm{ml}$. To co- culture these cells with three different supernatant sources of external inositol, $1 \mathrm{ml}$ of Aux cells were placed in each of six wells in the lower chamber of the culture dish. Cellular supernatant was obtained from Wt-MIP and MIP-GFP cells grown in minimal medium without inositol, while Aux cells were grown in complete medium, which has a minimal amount of inositol. After growing cells to an OD660 of $1.0\left(1.85 \times 10^{7}\right.$ cells per $\left.\mathrm{ml}\right)$, supernatant was isolated via centrifugation and sterilized, using a $0.2 \mu \mathrm{m}$ Nalgene rapid-flow sterile filter. Sterile supernatant $(1 \mathrm{ml})$, containing either Wt-MIP proteins, Aux, no MIP proteins, or MIP-GFP reporter proteins, was placed in the upper chamber in wells containing permeable membranes with an extremely small pore size, $0.4 \mu \mathrm{m}$. Aux cells in the lower chamber of the culture plate were removed after incubation at $30{ }^{\circ} \mathrm{C}$ for $24 \mathrm{~h}$ in the presence of different cellular supernatants as sources of external inositol, quantitated using a Genesys 2 spectrophotometer, and examined for MIP expression using confocal microscopic analyses. Three co-culturing experiments were performed, using isolated supernatants. 


\section{Imaging Aux cells grown in diverse supernatant sources of external inositol}

A Zeiss Axioscope 40 confocal microscope with differential interference contrast (DIC) imaging capacity was used to visualize yeast cells with both visible and UV wavelengths. One $\mathrm{ml}$ of auxotrophic cells, located in the lower chamber of the culture dish, was removed, centrifuged, washed $2 \mathrm{X}$ in minimal medium with no inositol, and evaluated for MIP expression. Fluorescence was observed with wavelengths from 395 to $580 \mathrm{~nm}$. Cells were examined for contamination by switching wavelengths and evaluating cells for continued glow under FITC, YFP, Cherry, and TRIC settings. Common bacteria tend to give off fluorescence in a full spectrum of colors and are identified by this technique [43].

\section{Assessing structural and functional conservation of MIP-GFP}

Protein models of Wt-MIP and MIP-GFP proteins were generated in SWISS-MODEL [61], PHYRE-2 [62] and I-TASSER [63]. All models were compared to crystal structures of MIP, located at the RCSB Protein Database (www.rcsb.org). Sequence homology and secondary structure were examined in Chimera 1.14 [64]. In all models generated by SWISS-MODEL, MIP and GFP were two separate 3D structures. Further examination of the protein sequence in Chimera 1.14 showed that the program removed GFP protein sequence from MIP protein sequence. Models generated by I-TASSER accurately generated GFP but not MIP. Examination of MIP active sites, predicted by I-TASSER, showed non-conserved amino acids, as defined by site directed mutagenesis [65, 67] Models examined in Chimera 1.14 showed errors in MIP secondary structure based on comparison to MIP crystal structures. Only models produced by PHYRE-2 were selected because this software was able to extract a MIP-GFP fusion protein. In addition to similarity to known protein sequences, PHYRE2 used protein structure prediction to generate $3 \mathrm{D}$ protein structures. Superimposed models and RMSDs]were produced using SuperPose [66]. Models shown in (Fig. 3) were colored in Chimera 1.14. [64].

\section{Acknowledgements}

The authors are indebted to Dr. Susan Henry for providing wild-type and mutant yeast strains, Dr. Patricia McGraw for sharing yeast anti-MIP antibody, Dr. Kimberly Lackey for assistance with sample preparations for confocal studies, and Dr. Harriet Smith-Sommerville for assisting with sample preparation for TEM microscopy.

\section{Authors' contributions}

ES Funding acquisition, Methodology, Investigation, Formal analysis, Visualization. HDA-Writing, review \& editing. MV—Methodology, Investigation. MEH - Methodology, Investigation MDJ Conceptualization, Supervision, Writing - original draft, Validation. All authors read and approved the final manuscript.
Funding

Financial support was provided by the Southern Regional Education Board and the Department of Biological Sciences at The University of Alabama.

\section{Availability of data and materials}

Tools and materials used to generate data from this research, antibody and yeast strains, were gifts as acknowledged in acknowledgements.

\section{Declarations}

\section{Ethics approval and consent to participate}

My co-authors and I warrant that this article is original and that no parts of it has been formally published and that I am authorized by my co-authors to enter into this arrangement.

\section{Consent for publication}

My co-authors and I agree to publish article in Microbial Cell Factories.

\section{Competing interests}

The authors declare no competing financial or intellectual interests.

\section{Author details}

${ }^{1}$ The University of Alabama, The Institute of Social Science Research, PO Box 8702161, Tuscaloosa, AL 35487, USA. ²Department of Biological Sciences, School of Science, The University of Jordan, PO Box 11942, Amman-Jordan, Jordan. ${ }^{3}$ Department of Biological Sciences, The University of Alabama, PO Box 870344, Tuscaloosa, AL 35487, USA

Received: 24 July 2020 Accepted: 8 June 2021

Published online: 19 July 2021

References

1. Michell RH. Inositol derivatives: evolution and functions. Nat Rev Mol Cell Biol. 2008;9:151-61

2. Alebous HD, Cartee R, Vaccari D, Wright OA, Ahmed A, Hood RD, DeanJohnson M. Developmental control of inositol phosphate biosynthesis is altered in the brain of both curly and phenotypically normal straight tail mutant mice. Birth Defects Res A Clin Mol Teratol. 2009;85:822-7.

3. Payrastre B, Gaits-lacovoni F, Sansonetti P, Tronchère H. Phosphoinositides and cellular pathogens. Subcell Biochem. 2012;59:363-88.

4. Michell RH. Inositol lipids: from an archaeal origin to phosphatidylinositol 3,5-bisphosphate faults in human disease. FEBS J. 2013;280:6281-94.

5. Latrasse D, Jégu T, Meng PH, Mazubert C, Hudik E, Delarue M, Charon C, Crespi M, Hirt H, Raynaud C, et al. Dual function of MIPS1 as a metabolic enzyme and transcriptional regulator. Nucleic Acids Res. 2013;41:2907-17.

6. Loewus FA, Loewus MW. myo-Inositol:Biosynthesis and metabolism, in: Jack Preiss, Carbohydrates: Structure and Function: Biochemistry of Plants. Elsevier. 2014: 43- 69.

7. Shears SB. Intimate connections: Inositol pyrophosphates at the interface of metabolic regulation and cell signaling. J Cell Physiol. 2018;233:1897-912.

8. Regidor PA, Schindler AE, Lesoine B, Druckman R. Management of women with PCOS using myo-inositol and folic acid. New clinical data and review of the literature. Horm Mol Biol Clin Investig. 2018. Doi: https://doi.org/10.1515/hmbci-2017-0067.

9. Showell MG, Mackenzie-Proctor R, Jordan V, Hodgson R, Farquhar C. Inositol for subfertile women with polycystic ovary syndrome. Cochrane Database Syst Rev. 2018. https://doi.org/10.1002/14651858.CD012378. pub2.

10. Majumder AL, Dean-Johnson M, Henry SA. 1L-myo-inositol-1-phosphate synthase. Biochim Biophys Acta. 1997;1348:245-56.

11. Hazra A, Nandy P. Myo-inositol 1-phosphate synthase-the chosen path of evolution. Biotechnologia. 2016;97:95-108.

12. Eisenberg F Jr, Parthasarathy R. Measurement of biosynthesis of myoinositol from glucose-6- phosphate. Methods Enzymol. 1987;141:127-43.

13. Wong $\mathrm{YH}$, Kalmbach SJ, Hartman BK, Sherman WR. Immunohistochemical staining and enzyme activity measurements show 
myo-inositol-1- phosphate synthase to be localized in the vasculature of brain. J Neurochem. 1987:48:1434-42.

14. Lackey KH, Pope PM, Dean-Johnson M. Biosynthesis of Inositol Phosphate in organelles of Arabidopsis thaliana. SAAS Bull Biochem Biotech. 2002;15:8-15.

15. Lackey KH, Pope PM, Dean-Johnson M. Expression of 1L-myoinositol1-phosphate synthase in organelles. Plant Physiol. 2003;132:2240-7.

16. Rodrigues ML, Nakayasu ES, Oliveira DL, Nimrichter L, Nosanchuk JD, Almeida IC, Casadevall A. Extracellular vesicles produced by Cryptococcus neoformans contain protein components associated with virulence. Eukaryot Cell. 2008;7:58-67.

17. Oliveira DL, Nakayasu ES, Joffe LS, Guimarães AJ, Sobreira TJ, Nosanchuk JD, Cordero RJ, Frases S, Casadevall A, Almeida IC, et al. Characterization of yeast extracellular vesicles: evidence for the participation of different pathways of cellular traffic in vesicle biogenesis. PLOS ONE. 2010. https:// doi.org/10.1371/journal.pone.0011113.

18. Dean-Johnson M, Wang X. Differentially expressed forms of 1-L-myoinositol-1- phosphate synthase in Phaseolus vulgaris. J Biol Chem. 1996;271:17215-8.

19. Nombela C, Gil C, Chaffin WL. Non-conventional protein secretion in yeast. Trends Microbiol. 2006;14:15-21.

20. Chiera J, Grabau E. Localization of myo-inositol phosphate synthase (GmMIPS-1) during the early stages of soybean seed development. J Exp Bot. 2007;58:2261-8.

21. Mitsuhashi N, Kondo M, Nakaune S, Ohnishi M, Hayashi M, HaraNishimura I, Richardson A, Fukaki H, Nishimura M, Mimura T. Localization of myo-inositol-1-phosphate synthase to the endosperm in developing seeds of Arabidopsis. J Exp Bot. 2008;59:3069-76.

22. Chen $\mathrm{H}$, Xiong L. Myo-Inositol-1-phosphate synthase is required for polar auxin transport and organ development. J Biol Chem. 2010;285:24238-47.

23. Bayer-Santos E, Aguilar-Bonavides C, Rodrigues SP, Cordero EM, Marques AF, Varela- Ramirez A, Choi H, Yoshida N, da Silveira JF, Almeida IC. Proteomic analysis of Trypanosoma cruzi secretome: characterization of two populations of extracellular vesicles and soluble proteins. J Proteome Res. 2013;12:883-97.

24. Bravo-Sagua R, Torrealba N, Paredes F, Morales PE, Pennanen C, LópezCrisosto C, Troncoso R, Criollo A, Chiong M, Hill JA, et al. Organelle communication: signaling crossroads between homeostasis and disease. Int J Biochem Cell Biol. 2014:50:55-9.

25. Gangoda L, Boukouris S, Liem M, Kalra H, Mathivanan S. Extracellular vesicles including exosomes are mediators of signal transduction: Are they protective or pathogenic?. Proteomics. 2015;15: 260-271.

26. Iraci N, Leonardi T, Gessler F, Vega B, Pluchino S. Focus on extracellular vesicles: physiological role and signalling properties of extracellular membrane vesicles. Int J Mol Sci. 2016;17:171.

27. McGough IJ, Vincent JP. Exosomes in developmental signaling. Development. 2016;143:2482-93.

28. Raposo G, Stahl PD. Extracellular vesicles: a new communication paradigm? Nat Rev Mol Cell Biol. 2019;20:509-10.

29. Hosseini-Beheshti E, Grau GER. Extracellular vesicles and microvascular pathology: decoding the active dialogue. Microcirculation. 2019. https:// doi.org/10.1111/micc. 12485.

30. Steenbeek SC, Pham TV, Ligt JD, Zomer A, Knol JC, Piersma SR, Schelfhorst T, Cuppen E, Jimenez CR, Van Rheenen J. 10 Extracellular vesicles that carry signalling networks drive phenocopying of migratory behaviour between cancer cells in vivo. ESMO Open. 2018. https://doi.org/10.1136/ esmoopen-2018-EACR25.10.

31. Sáez T, Toledo F, Sobrevia L. Impaired signalling pathways mediated by extracellular vesicles in diabesity. Mol Aspects Med. 2019;66:13-20.

32. Mäger I, Willms E, Bonner S, Hill AF, Wood MJA. Extracellular vesicles in neurodegenerative disorders. In: Edelstein LS, JR; Quesenberry,PJ; Noble D, ed. Exosomes : a clinical compendium: Elsiever. 2020.

33. Mulcahy LA, Pink RC, Carter DR. Routes and mechanisms of extracellular vesicle uptake. J Extracell Vesicles. 2014;3:24641.

34. Horibe S, Tanahashi T, Kawauchi S, Murakami Y, Rikitake Y. Mechanism of recipient cell- dependent differences in exosome uptake. BMC Cancer. 2018;18:47.

35. Ofir-Birin Y, Abou Karam P, Rudik A, Giladi T, Porat Z, Regev-Rudzki N. Monitoring extracellular vesicle cargo active uptake by imaging flow cytometry. Front Immunol. 2018;9:1011.
36. Durak-Kozica M, Baster Z, Kubat K, Stępień E. 3D visualization of extracellular vesicle uptake by endothelial cells. Cell Mol Biol Lett. 2018;23:57.

37. Gatien J, Mermillod P, Tsikis G, Bernardi O, Janati Idrissi S, Uzbekov R, Le Bourhis D, Salvetti P, Almiñana C, Saint-Dizier M. Metabolomic, profile of oviductal extracellular vesicles across the estrous cycle in cattle. Int J Mol Sci. 2019;20:6339.

38. Wang M, Dean RA. Movement of small RNAs in and between plants and fungi. Mol Plant Pathol. 2020; 21: 589-601.

39. Grobstein C. Morphogenetic interaction between embryonic mouse tissues separated by a membrane filter. Nature. 1953;172:869-70.

40. Duan $P, X u H$, Zeng $Y$, Wang $Y$, Yin ZQ. Human bone marrow stromal cells can differentiate to a retinal pigment epithelial phenotype when cocultured with pig retinal pigment epithelium using a transwell system. Cell Physiol Biochem. 2013;31:601-13.

41. Wu Z, Liu W, Wang Z, Zeng B, Peng G, Niu H, Wu Z, Liu W, Wang Z, Zeng B, et al. Mesenchymal stem cells derived from iPSCs expressing interleukin-24 inhibit the growth of melanoma in the tumor- bearing mouse model. Cancer Cell Int. 2020. https://doi.org/10.1186/s12935-020-1112-7.

42. Kucharzyk KH, Deshusses MA, Porter KA, Hsu-Kim H. Relative contributions of mercury bioavailability and microbial growth rate on net methylmercury production by anaerobic mixed cultures. Environ Sci Process Impacts. 2015;17:1568-77.

43. Cumberland S, Bridgeman J, Baker A, Sterling M, Ward D. Fluorescence spectroscopy as a tool for determining microbial quality in potable water applications. Environ Technol. 2012;33:687-93.

44. van Niel G, D'Angelo G, Raposo G. Shedding light on the cell biology of extracellular vesicles. Nat Rev Mol Cell Biol. 2018;19:213-28.

45. Fernandez S, Homann MJ, Henry SA, Carman GM. Metabolism of the phospholipid precursor inositol and its relationship to growth and viability in the natural auxotroph Schizosaccharomyces pombe. J Bacteriol. 1986;166:779-86.

46. Ingavale SS, Bachhawat AK. Restoration of inositol prototrophy in the fission yeast Schizosaccharomyces pombe. Microbiology. 1999;145:1903-10.

47. Porollo A, Sesterhenn TM, Collins MS, Welge JA, Cushion MT. Comparative genomics of pneumocystis species suggests the absence of genes for myo- inositol synthesis and reliance on inositol transport and metabolism. MBio. 2014. https://doi.org/10.1128/MBIO.01834-14.

48. Thomas MP, Mills SJ, Potter BV. The "Other" Inositols and Their Phosphates: Synthesis, Biology, and Medicine (with Recent Advances in myo-Inositol Chemistry). Angew Chem InEd Engl. 2016;55:1614-50.

49. Rodrigues ML, Casadevall A. A two-way road: novel roles for fungal extracellular vesicles. Mol Microbiol. 2018;1 10(1):11-5. https://doi.org/10.1111/ mmi.

50. You R, Wang L, Shi C, Chen H, Zhang S, Hu M, Tao Y. Efficient production of myo-inositol in Escherichia coli through metabolic engineering. Microbial Cell Factor. 2020;19:1.

51. Klig LS, Henry SA. Isolation of the yeast INO1 gene: located on an autonomously replicating plasmid, the gene is fully regulated. Proc Natl Acad Sci USA. 1984:81:3816-20.

52. Dean-Johnson M, Henry SA. Biosynthesis of inositol in yeast. Primary structure of myo- inositol-1- phosphate synthase (EC 5.5.1.4) and functional analysis of its structural gene, the INO1 locus. J Biol Chem. 1989:264:1274-83.

53. Niedenthal RK, Riles L, Johnston M, Hegemann JH. Green fluorescent protein as a marker for gene expression and subcellular localization in budding yeast. Yeast. 1996;12:773-86.

54. Mullis KB. The unusual origin of the polymerase chain reaction. Sci Am. 1990;262:56-61.

55. Southern EM. Detection of specific sequences among DNA fragments separated by gel electrophoresis. J Mol Biol. 1975;98:503-17.

56. Huh WK, Falvo JV, Gerke LC, Carroll AS, Howson RW, Weissman JS, O'Shea EK. Global analysis of protein localization in budding yeast. Nature. 2003;425:686-91.

57. Barnett JEG, Brice RE, Corina DL. A colorimetric determination of inositol monophosphates as an assay for d-glucose 6-phosphate-1 I-myo inositol 1-phosphate cyclase. Biochem J. 1970;119:183-6.

58. Carman GM, Fischl AS. Phosphatidylinositol synthase from yeast. Methods Enzymol. 1992;209:305-12. https://doi.org/10.1016/0076-6879(92) 09038-5.

59. Wright R. Transmission electron microscopy of yeast. Microsc Res Tech. 2000;51:496-510 
60. Culbertson MR, Henry SA. Inositol-requiring mutants of Saccharomyces cerevisiae. Genetics. 1975;80(23-40):6162.

61. Biasini M, Bienert S, Waterhouse A, Arnold K, Studer G, Schmidt T, Kiefer F, Gallo Cassarino T, Bertoni M, Bordoli L, Schwede T. SWISS-MODEL: modelling protein tertiary and quaternary structure using evolutionary information. Nucleic Acids Res. 2014. https://doi.org/10.1093/nar/gku340.

62. Kelley LA, Mezulis S, Yates CM, Wass MN, Sternberg MJ. The Phyre2 web portal for protein modeling, prediction and analysis. Nat Protoc. 2015:10:845-58

63. Yang J, Yan R, Roy A, Xu D, Poisson J, Zhang Y. The I-TASSER Suite: protein structure and function prediction. Nat Methods. 2015;12:7-8.

64. Pettersen EF, Goddard TD, Huang CC, Couch GS, Greenblatt DM, Meng EC, Ferrin TE. UCSF Chimera-a visualization system for exploratory research and analysis. J Comput Chem. 2004;25:1605-12.

65. Basak P, Maitra-Majee S, Das JK, Mukherjee A, Ghosh Dastidar S, Pal Choudhury P, Lahiri Majumder A. An evolutionary analysis identifies a conserved pentapeptide stretch containing the two essential lysine residues for rice L-myo-inositol 1-phosphate synthase catalytic activity. PLoS ONE. 2017. https://doi.org/10.1371/journal.pone.0185351.

66. Maiti R, Van Domselaar GH, Zhang H, Wishart DS. SuperPose: a simple server for sophisticated structural superposition. Nucleic Acids Res. 2004. https://doi.org/10.1093/nar/gkh477.

67. Azam SS, Sarfaraz S, Abro A. Comparative modeling and virtual screening for the identification of novel inhibitors for myo-inositol-1-phosphate synthase. Mol Biol Rep. 2014;41:5039-52.

\section{Publisher's Note}

Springer Nature remains neutral with regard to jurisdictional claims in published maps and institutional affiliations.
Ready to submit your research? Choose BMC and benefit from:

- fast, convenient online submission

- thorough peer review by experienced researchers in your field

- rapid publication on acceptance

- support for research data, including large and complex data types

- gold Open Access which fosters wider collaboration and increased citations

- maximum visibility for your research: over $100 \mathrm{M}$ website views per year

At BMC, research is always in progress.

Learn more biomedcentral.com/submissions 